\title{
Effect of treatment on immune responsiveness in lepromatous leprosy patients
}

\author{
DANUZA A ESQUENAZI, ELISABETH P SAMPAIO, \\ ANDRE L MOREIRA, MARIA E N GALLO, \\ SONIA M R ALMEIDA \& EUZENIR N SARNO* \\ Leprosy Unit, Oswaldo Cruz Foundation, Av. Brasil, 4365 \\ Manguinhos, CEP 21.040 Rio de Janeiro, Brazil
}

Accepted for publication 30 March 1990

\begin{abstract}
Summary This study was performed in order to analyse whether the immune unresponsiveness to Mycobacterium leprae, largely seen in lepromatous patients, persisted after discharge from treatment. Lymphoproliferation and skin tests were performed using two mycobacterial antigens ( $M$. leprae and BCG) in three groups of lepromatous patients grouped by treatment status. Forty-seven per cent of the lepromatous patients tested acquired reactivity to $M$. le prae af ter long-term treatment.
\end{abstract}

\section{Introduction}

Lepromatous leprosy patients (LL or BL forms) display a selective immunological unresponsiveness to Mycobacterium leprae antigen with the absence of delayed-typehypersensitivity, ${ }^{1} \mathrm{~T}$-cell proliferation, ${ }^{2}$ and deficiency in the production of growth factors such as IL-2. ${ }^{3}$ These patients also fail to produce interferon-gamma (IFN- $\gamma$ ) in response to M. leprae. ${ }^{4}$ Active suppression by macrophages and/or T cells may explain their inability to respond to leprosy bacilli. ${ }^{5,6}$ Lepromatous patients carry a high load of bacilli which may play a role invivo in the induction of immune tolerance. ${ }^{7}$ Cellular anergy observed in lepromatous patients appears to be $M$. leprae specific since the immune response against other antigens is largely normal. ${ }^{8}$

The effect of treatment on the recovery from the immunological anergy in lepromatous patients is a controversial subject. Findings from a number of studies suggest that an unresponsiveness to $M$. leprae seen in lepromatous patients is long-lasting and unrelated to the bacterial load. ${ }^{9}{ }^{10}$ However, some studies have revealed different immunological reactivity to mitogens and mycobacterial antigens when cellular immune responses of short-term treated patients were compared with untreated patients. ${ }^{11-15}$

To determine the effect of long-term treatment on the immune status of patients, we

* Corresponding author. 
have assessed the cellular immune responses of 64 lepromatous patients to $M$. leprae and to BCG.

\section{Materials and methods}

\section{PATIENTS}

Sixty-four multibacillary leprosy patients who attended the Outpatient Unit of the Oswaldo Cruz Foundation, Rio de Janeiro, Brazil, were included in this study. Forty-one patients were diagnosed as borderline lepromatous (BL) and twenty-three were classified as polar lepromatous (LL) according to Ridley-Jopling classification. ${ }^{16}$ The patients were grouped by length of treatment. Twenty-four patients were recently diagnosed and had received no treatment (NT) at the time of the study. Twenty-five patients were on multidrug therapy, ranging from 2 to 15 months (on treatment, OT). Fifteen patients had received monotherapy with dapsone from between 10 to 30 years (mean 16.6 years) and had terminated therapy from 1 to 6 years prior to participation in this study. Patients in this group, designated AT (after treatment) were without lesions and had negative lymph smears for acid-fast bacilli (AFB). None of the patients included in this study presented episodes of reaction during the study.

\section{LEPROMIN SKIN TEST}

Armadillo-derived lepromin (NHDC, Carville, USA, 3-4 $\times 10^{7}$ bacilli $/ \mathrm{ml}$ ) was injected intradermally in the forearm and the reaction was measured 3 to 4 weeks after the injection (late lepromin reaction). Induration $\geq 3 \mathrm{~mm}$ was considered positive.

\section{LYMPHOPROLIFERATION ASSAY}

Heparinized blood was collected under sterile conditions from the patients and mononuclear leukocytes (PBL) were isolated by Ficoll-Hypaque gradient centrifugation. The cells were resuspended in RPMI 1640 (Gibco Lab.) supplemented with 10\% human AB serum, $100 \mathrm{U} / \mathrm{ml}$ penicillin and $100 \mu \mathrm{g} / \mathrm{ml}$ streptomycin and $2 \mathrm{mM}$ L-glutamine (complete medium). All proliferation assays were performed in microtitre wells in a final volume of $0.2 \mathrm{ml}$ complete medium. Stimulation with antigen was carried out for 6 days at $37^{\circ} \mathrm{C}$ in a $5 \% \mathrm{CO}_{2}$ atmosphere. For these experiments, $2 \times 10^{5} \mathrm{PBL}$ were incubated with 20 $\mu \mathrm{g} / \mathrm{ml} \mathrm{M}$. leprae, or $25 \mu \mathrm{g} / \mathrm{ml} \mathrm{BCG}$ in triplicate. One $\mu \mathrm{Ci}$ per well of $\left[{ }^{3} \mathrm{H}\right]$ thymidine (Amersham Co., specific activity $6.7 \mathrm{Ci} / \mathrm{mM}$ ) was added $18 \mathrm{~h}$ before harvesting cells for measurement of radiolabelled thymidine incorporated into newly synthesized DNA. The results are expressed as stimulation index (SI) derived as the ratio of mean cpm cultures with antigen to the cpm of cultures without antigen. Proliferation to the antigen was considered positive for $\mathrm{SI} \geq 3 \cdot 0$.

\section{ANTIGENS}

M. leprae was kindly provided by Dr R. J. W. Rees (IMMLEP Bank, Mill Hill, England) and BCG was obtained from the Ataulfo de Paiva Foundation, Rio de Janeiro, Brazil. 


\section{STATISTICAL ANALYSIS}

For comparison of the cellular immune response to $M$. leprae and $\mathrm{BCG}$ among the groups, Student's $t$-test and the Mann-Whitney test were used.

\section{Results}

\section{LEPROMIN TEST}

As expected, all the patients in NT and OT groups showed a negative lepromin skin test. In AT group, four patients developed a skin-test reaction; however, no correlation with the duration of treatment was noted (Table 1). Before the onset of treatment all patients in the AT group had negative skin tests (data not shown).

\section{LYMPHOPROLIFERATION ASSAY}

The number of $M$. leprae nonresponders was significantly lower in the AT group in comparison to that of the NT and OT patients $(p<0 \cdot 05)$. Of the AT patients $53.4 \%$ were unresponsive to $M$. leprae (SI < 3.0) (Figure 1). In contrast, $95 \cdot 8 \%$ and $92 \%$ of the NT and OT patients, respectively, failed to respond to leprosy bacilli. There was no difference between the response of LL and BL patients in any of the groups studied. However, a significant difference was found between the mean SI of AT group as compared to the NT

Table 1. Particulars of the individuals of the after treatment lepromatous patients group

\begin{tabular}{|c|c|c|c|c|c|}
\hline Name & $\begin{array}{l}\text { Histopathology } \\
\text { classification }\end{array}$ & $\begin{array}{l}\text { Lepromin } \\
\text { test } \dagger\end{array}$ & $\begin{array}{l}\text { In vitro test } \\
\text { to } M \text {. leprae } \\
\text { antigen }\end{array}$ & $\begin{array}{c}\text { Time of treatment } \\
\text { until became } \\
\text { negative to } \\
\text { bacilloscopy (years) }\end{array}$ & $\begin{array}{c}\text { Time of } \\
\text { total treatment } \\
\quad \text { (years) }\end{array}$ \\
\hline $\mathrm{RCN}$ & BL & NEG. & POS.* & 04 & 16 \\
\hline TSS & BL & $2 \mathrm{~mm}$ & POS * & 20 & 25 \\
\hline PCP & BL & NEG. & POS.* & 05 & 18 \\
\hline NAN & BL & NEG. & POS.* & 08 & 13 \\
\hline AM & BL & NEG. & POS. & 06 & 11 \\
\hline SBC & LL & NEG. & POS $* \ddagger$ & 10 & 16 \\
\hline $\mathrm{CN}$ & BL & NEG. & POS.* & 08 & 14 \\
\hline MLB & BL & $2 \mathrm{~mm}$ & NEG. & 05 & 10 \\
\hline JLL & LL & NEG. & NEG.* & 08 & 17 \\
\hline SSM & BL & NEG. & NEG. & 10 & 17 \\
\hline SDR & BL & $4 \mathrm{~mm}$ & NEG. & 08 & 16 \\
\hline $\mathrm{CA}$ & BL & $3 \mathrm{~mm}$ & NEG. & 03 & 12 \\
\hline YST & LL & NEG. & NEG. & 08 & 16 \\
\hline ASM & BL & NEG. & NEG. $\ddagger$ & 05 & 18 \\
\hline SML & BL & NEG. & NEG. & 20 & 30 \\
\hline
\end{tabular}

* Presence of frequent episodes of erythema nodosum leprosum (ENL) during the time of treatment.

$\dagger$ All patients had a negative lepromin skin test at the beginning of treatment.

$\ddagger$ Relapse of the disease with leprosy lesion compatible to the indeterminate form with $\mathrm{AFB}^{+}$in the skin biopsy. 


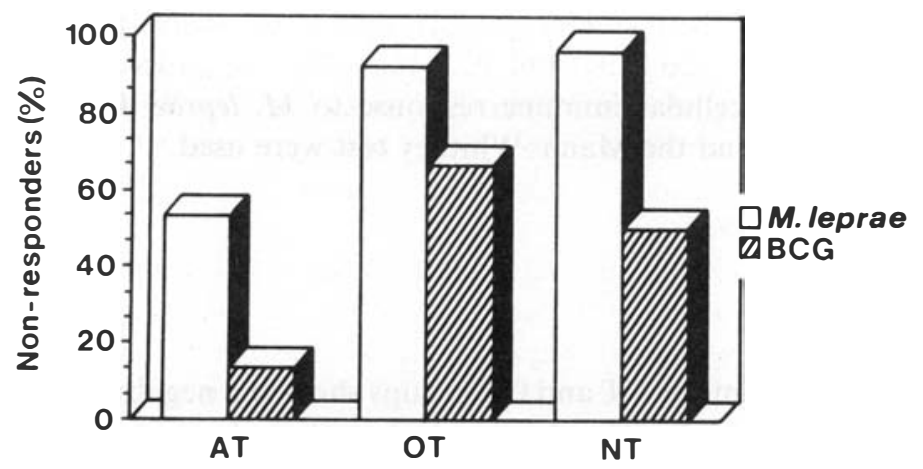

Figure 1. Relationship between treatment and response to Mycobacterium leprae. PBL from patients after treatment (AT) $(n=15)$, on treatment (OT) $(n=25)$, and untreated (NT) $(n=25)$ were stimulated with $M$. leprae or BCG. Proliferation to antigen was considered negative for $\mathrm{SI}<3 \cdot 0$.

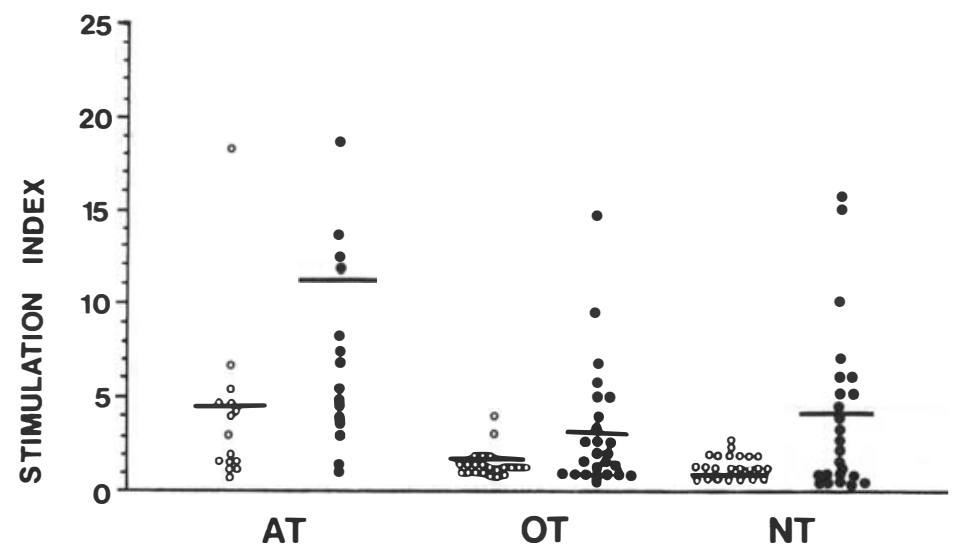

Figure 2. Proliferative responses of PBL from patients with lepromatous leprosy. Each point represents the SI of PBL from each patient and the bars represent the mean SI in each group, as described in the legend of Figure 1. A SI $\geq 3$ was considered a positive response. There was a significant difference between the response to Mycobacterium leprae $(P<0.05)$ and BCG $(P<0.02)$, when the AT group was compared to NT and OT groups (Student's $t$-test).

and OT patients $(p<0.05)$. The AT group mean SI was 4.2 (ranging from 0.9 to 18.8$)$ in comparison to mean SI of 1.5 (ranging from 0.5 to 3.0 ) in the NT group and 1.04 (ranging from 0.2 to $4 \cdot 0$ ) among the OT group (Figure 2). To determine whether the duration of treatment was correlated to the $M$. leprae response in the AT patients, we divided this group into responders and nonresponders. Among the $8(53 \cdot 3 \%)$ responder patients, the mean treatment time was $16 \cdot 2 \pm 4.5$ years, while in the group that remained unresponsive, the mean duration of treatment was $17 \cdot 0 \pm 5 \cdot 0$ years. No statistical difference was observed between the nonresponder and responder patients with regard to the duration of treatment before their lymph smear became AFB negative $(8.7 \pm 5.3$ years for the responder patients $v s .8 \cdot 3 \pm 5 \cdot 2$ years for the nonresponders). 
During the course of these studies, two $M$. leprae responsive patients from the AT group developed lesions clinically and histologically compatible with indeterminate leprosy, and rare AFB was seen in the skin biopsies (Table 1). With regard to reactional states, it is important to note that 7 patients $(46 \cdot 6 \%)$ of the AT group had erythema nodosum leprosum during their course of treatment. All but one showed a positive response to $M$. leprae in this study.

Stimulation with BCG, similarly, evoked a higher response in PBL from patients in the AT group as compared to the OT and NT groups $(p<0.02)$. As shown in Figure 2, the mean SI for AT patients was 7.52 compared to 3.44 and 4.20 in the OT and NT patients. All patients showing a positive response to $M$. leprae ( 1 patient in the NT group, 2 patients in the OT group, and 7 patients in the AT group) were also responsive to BCG.

\section{Discussion}

The present study supports previous findings concerning the lack of cellular immune response to $M$. leprae in LL and BL patients. While the majority $(80.7 \%)$ of the patients included in this study did not respond to $M$. leprae $(\mathrm{SI}<3 \cdot 0 \%$ ), only $30 \%$ were unresponsive to BCG. However, when patients from the whole spectrum of leprosy were compared to household contacts, a good correlation was found between the response to M. leprae and BCG. ${ }^{17}$

When lepromatous patients were grouped by their treatment status, the percentage of $M$. leprae nonresponders was significantly lower among the long-term treated patients (AT) compared to untreated, newly diagnosed patients (NT) and the short-term treated (OT) patients. Likewise, the number of BCG responsive patients also increased after treatment. The number of responder patients was higher, and an intensified response was observed to both M. leprae and BCG as evaluated by the mean SI. This is another indication that the continuous presence of mycobacteria could contribute to the depression of the host's cellular immunity.

The improved immune response to BCG demonstrated that the unresponsiveness in lepromatous patients is not restricted to $M$. leprae. Reitan et al. ${ }^{18}$ have, similarly, observed that PPD evokes a stronger reaction in PBL from treated patients as compared to the untreated leprosy patients. An improved response to mitogens in treated patients has also been reported. ${ }^{19}$ The long-lasting unresponsiveness seen in almost half of the long-term treated patients might support the hypothesis which attributes the absence of responsiveness in LL patients to genetic factors, ${ }^{20}$ absence of $M$. leprae-reactive T cells from the circulation ${ }^{1}$ or the presence of suppressor mechanisms. ${ }^{5,6}$ However, reversion of the unresponsiveness of lepromatous patients has been documented in many reports under different clinical and experimental conditions. ${ }^{4,7,9,14,21}$

The immune reactivity observed after chemotherapy suggests that the unresponsiveness in lepromatous patients might not be long lasting and unchangeable in all cases. The inability to kill and clear bacteria during the early phase of infection could result in a high antigenic load which may in turn induce a tolerant state. Recent studies have demonstrated that immune tolerance may develop in the presence of a high concentration of antigen ${ }^{22}$ and this state may be reversed after decreasing the antigenic load. ${ }^{23}$

The fact that many of the $M$. leprae patients in the AT group had previously presented episodes of ENL during the course of treatment raises the hypothesis that M. leprae- 
reactive T cells had emerged during the reactional stages. ${ }^{24}$ Waldorf et al. ${ }^{25}$ have reported similar findings using skin tests to assess immune responses in leprosy patients. Lepromatous patients with ENL showed higher positivity to DNCB sensitization as compared to patients without ENL.

Taken together, findings from the present investigation support the hypothesis that reduction in $M$. leprae post-therapy may contribute to the reversal of unresponsiveness in some lepromatous patients.

\section{Acknowledgments}

Part of these studies were funded by the UNDP/World Bank/WHO special programme for research and training in tropical diseases. The authors are in debt to Dr Nahid Mohagheghpour for her assistance and advice.

\section{References}

1 Godal T, Myklestad B, Samuel DR, Myrvang B. Characterization of the cellular immune defect in lepromatous leprosy: a specific lack of circulating $M$. leprae reactive lymphocytes. Clin exp Imm, 1971; 9: $821-31$.

${ }^{2}$ Haregewoin A, Godal T, Mustafa AS, Belehu A, Yemaneberhan Y. T-cell conditioned media reverse T-cell unresponsiveness in lepromatous leprosy. Nature (Lond), 1983; 303: 342-4.

${ }^{3}$ Haregewoin A, Longley J, Bjune G, Mustafa AS, Godal T. The role of interleukin-2 (IL-2) in the specific unresponsiveness of lepromatous leprosy to Mycobacterium leprae studies in vitro and in vivo. Immunol Letters, 1985; 11: 249-52.

4 Nogueira N, Kaplan G, Levy E, Sarno EN, Kushner P, Granelli-Piperno A, Vieira LMM, Gould VC, Lewis W, Steinman R, Yip YK, Cohn ZA. Defective interferon-gamma production in leprosy. Reversal with antigen and interleukin-2. $J$ exp Med, 1983; 158: 165-70.

5 Sathish M, Bhutani LK, Sharma AK, Nath I. Monocyte-derived soluble suppressor factor(s) in patients with lepromatous leprosy. Infect Immunol, 1983; 42: 890-9.

6 Mehra V, Convit J, Rubinstein A, Bloom B. Activated suppressor T-cell in leprosy. J Immunol, 1982; 129: 1946-51.

7 Mohagheghpour N, Gelber RR, Engleman EG. T-cell def ect in lepromatous leprosy is reversible in vitro in the absence of exogenous growth factors. J Immunol, 1987; 138: 570-4.

8 Myrvang B, Godal T, Ridley DS, Froland S, Song YK. Immune responsiveness to Mycobacterium leprae and other mycobacterial antigens throughout the clinical and histopathological spectrum of leprosy. Clin exp Imm, 1963; 14: 541-53.

9 Kaplan G, Weistein D, Steinman RM, Levis WR, Elvers U, Patarroyo ME, Cohn Z. An analysis of invitro Tcell responsiveness in lepromatous leprosy. J exp Med, 1985; 162: 917-29.

10 Nath I, Curtis J, Sharma AK, Talwar GP. Circulating T-cell numbers and their mitogenic potential in leprosy-correlation with mycobacterial load. Clin exp Imm, 1977; 29: 393-400.

11 Mehra VL, Talwar GP, Balakrishnam K, Bhutani LK. Influence of chemotherapy and serum factors on the mitogenic response of peripheral leukocytes of leprosy patients to phytohaemagglutinin. Clinexp Imm, 1972; 12: 205-13.

12 Closs O, Reitan LJ, Negassi K, Harboe M, Belehu A. Invitro stimulation of lymphocytes in leprosy patients, healthy contacts of leprosy patients and subjects not exposed to leprosy. Scand J Immunol, 1982; 16: 103-15.

13 Tan Trao V, Huong PLT, Thuan AT, Long HT, Trach DD, Wrigth EP. Responses to Mycobacterium leprae by lymphocytes from new and old leprosy patients: role of exogenous lymphokines. Ann Inst Pasteur Immunol, 1988; 139: 121-33.

14 Cree IA, Smith WCS, Rees RJW, Swanson Beck J. The influence of antimycobacterial chemotherapy on delayed hypersensitivity skin-test reactions in leprosy patients. Lepr Rev, 1988; 59: 145-51.

15 Rao SSL, Stanley JNA, Kiran KU, Dharma Rao T, Rao PR, Pearson JMH. The effect of dapsone in high and normal dosage on the clinical and cell-mediated immune status of patients with borderline (BT-BL) leprosy. Lepr Rev, 1986; 57: 19-26. 
16 Ridley DS, Jopling WH. Classification of leprosy according to immunity: a five group system. Int J Lepr, 1966; 34: 255-73.

17 Sarno EN, Espinosa M, Sampaio EP, Vieira LMM, Figueiredo AA, Miranda CF, Esquenazi D, Salgado JLF, Nogueira N. Immunological responsiveness to $M$. leprae and BCG antigen in 98 leprosy patients and their household contacts. Braz J Med Biol Res, 1988; 21: 461-70.

18 Reitan LJ, Closs O, Belehu A. In vitro lymphocyte stimulation in patients with lepromatous and borderline tuberculoid leprosy. The effect of dapsone treatment on the response to Mycobacterium leprae antigens. Tuberculin purified derivative and non-mycobacterial stimulants. Int J Lepr, 1982; 50: 455-66.

${ }_{19}$ Prasad HK, Mishra RS, Nath I. Phenolic glycolipid-I of Mycobacterium leprae induces general suppression of in vitro concanavalin-A responses unrelated to leprosy type. $J$ exp Med, 1987; 165: 239-44.

20 Prasad KVN, Mohamed All P. Some aspects in the epidemiology of leprosy. Lepr Rev, 1966; 38: 49-56.

${ }^{21}$ Convit J, Aranzazu N, Ulrich M, Pinardi ME, Reyes O, Alvarado J. Immunotherapy with a mixture of Mycobacterium leprae and BCG in different forms of leprosy and in Mitsuda-negative contacts. Int J Lepr, 1982; 50: 415-24.

${ }^{22}$ Feldmann M, Zanders ED, Lamb JR. Tolerance in T-cell clones. Immunol Today, 1985; 6(2): 58-62.

23 Morahan G, Allison J, Miller JFAP. Tolerance of Class I histocompatibility antigens expressed extrathymically. Nature (Lond), 1989; 339: 622-5.

${ }^{24}$ Laal S, Bhutani LK, Nath I. Natural emergence of antigen-reactive T-cells in lepromatous leprosy patients during erythema nodosum leprosum. Infect Immunol, 1985; 50: 887-92.

${ }^{25}$ Waldorf D, Sheagren J, Trautman J, Block J. Impaired delayed hypersensitivity in patients with lepromatous leprosy. Lancet, 1966; 8: 773-6. 